\title{
Konsep Ekowisata Dalam Perancangan Resort di Kabupaten Ciamis
}

\author{
Azka Inatsan Ghassani, Asep Yudi Permana, Indah Susanti \\ Program Studi Arsitektur, Universitas Pendidikan Indonesia \\ Jl. Dr. Setiabudhi No. 229 Bandung 40154 Jawa Barat - Indonesia
}

Email: azka.inatsanghassani@gmail.com; yudi.permana@upi.edu; indahsusanti@upi.edu

\begin{abstract}
ABSTRAK
Kabupaten Ciamis merupakan salah satu kabupaten yang berada di Provinsi Jawa Barat yang memiliki 10 prioritas rencana pembangunan, dimana salah satunya adalah pembangunan di sektor pariwisata oleh karena itu, sarana akomodasi berupa jasa penginapan pun semakin dibutuhkan. Keberadaan alam Ciamis yang masih asri, perancangan resort dengan tema ekowisata dibutuhkan, dimana diharapkan mampu memberikan kesadaran kepada pengunjung akan pentingnya menjaga kelestarian lingkungan, budaya setempat, dan hubungan sosial .Perancangan ini menampilkan bentuk bangunan yang mencirikan ciri khas bangunan di Kabupaten Ciamis.Tidak hanya pada bentuk bangunan, ciri khas Kabupaten Ciamis pun diperlihatkan pada penggunaan material batu kali bulat dan material yang menjadi potensi alam disana seperti bambu dan kayu.Hasil studi ini diharapkan pembaca dapat memperoleh informasi dan pengetahuan terutama mengenai penerapan tema ekowisata pada resort.
\end{abstract}

Kata Kunci : Ciamis, Resort, Ekowisata

\begin{abstract}
Kabupaten Ciamis is one of the regencies in West Java Province that has 10 priority development plans, one of which is development in the tourism sector, therefore, accommodation facilities in the form of lodging services are increasingly needed. The existence of Ciamis nature is still beautiful, the design of the resort with the theme of ecotourism is needed, which is expected to be able to provide awareness to visitors of the importance of preserving the environment, local culture, and social relations. in the shape of the building, the characteristics of Ciamis Regency are also shown in the use of round stone material and materials that have natural potential there such as bamboo and wood. The results of this study are expected to provide readers and information, especially regarding the application of ecotourism themes in resorts
\end{abstract}

Keywords : Ciamis, Resort, Ecotourism 


\section{PENDAHULUAN}

Keindahan alam dan budaya pada suatu daerah merupakan daya tarik untuk para wisatawan. Jawa Barat sebagai salah satu provinsi yang menjadi pusat budaya di pulau Jawa, memiliki lebih dari 300 destinasi wisata alam dan lebih dari 600 wisata budaya di Jawa Barat. Jika dilihat, pada saat ini permintaan pasar wisata dunia terhadap wisata alam dan wisata budaya terus mengalami peningkatan (Bappeda Provinsi Jawa Barat, 2017). Terlihat pada tabel di bawah ini bahwa wisatawan mancanegara maupun domestik yang datang ke Provinsi Jawa Barat pada tahun 2012-2016 pun terus mengalami peningkatan.

Tabel 1. 1 Jumlah Wisatawan Mancanegara dan Domestik di Provinsi Jawa Barat,2012-2016

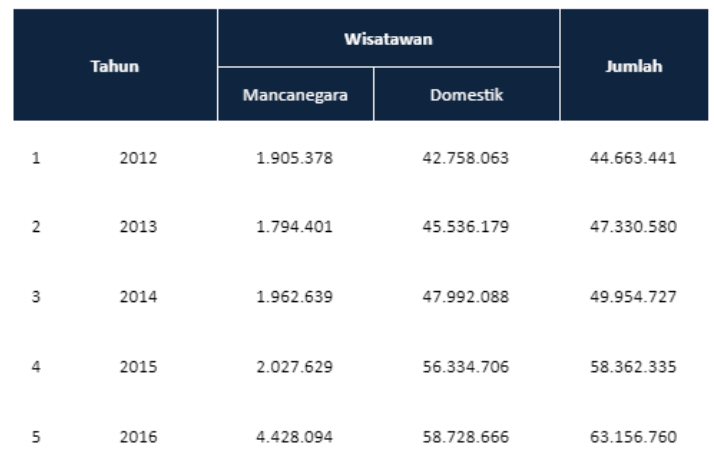

Sumber: Badan Pusat Statistik Provinsi Jawa Barat, 2018

Ciamis merupakan salah satu kabupaten yang berada di Provinsi Jawa Barat. Setelah resmi berpisah dengan Pangandaran pada tahun 2012, pemerintah daerah memiliki 10 prioritas rencana pembangunan, dimana salah satunya adalah pembangunan di sektor pariwisata. Dalam pariwisata, sarana dan prasarana pariwisata merupakan salah satu indikator berkembang atau tidaknya pariwisata (Dirjen Pariwisata, 1988).

Dalam rangka pembangunan sektor pariwisata di Kabupaten Ciamis, menjadikan sarana akomodasi berupa jasa penginapan semakin dibutuhkan. Dari penjelasan di atas, perancang tertarik untuk merancang sebuah kawasan resort, tidak hanya karena kebutuhan akan sarana akomodasi berupa penginapan bagi para wisatawan saja, keberadaan resort (Plataran L' Harmonie. 2017-2018) juga membantu pemerintah dalam program pembangunan daerah khususnya di sektor pariwisata. Dengan tema ekowisata yang diterapkan, resort ini diharapkan mampu memberikan kesadaran kepada pengunjung akan pentingnya menjaga kelestarian lingkungan, budaya setempat, dan hubungan social (Ischak, Setioko, dan Gandarum, 2018).

\section{METODOLOGI}

Pendekatan studi yang digunakan dalam penelitian ini menggunakan metode penelitian deskriptif kualitatif.. Teknik pengumpulan data adalah wawancara, observasi dan analisis dokumen. Sumber data dalam penelitian ini adalah narasumber, dokumen, dan pada lokasi penelitian di Cijeunjing, Kabupaten Ciamis.

\section{HASIL DAN PEMBAHASAN}

\subsection{KAJIAN TEORI}

\section{a. Definisi Resort}

Resort merupakan sebuah kawasan yang terencana yang memberikan kemudahan akomodasi kepada wisatawan dan didalamnya tidak hanya untuk menginap tetapi juga terdapat fasilitas rekreasi (Gee, Chuck Y., 1988). 


\section{b. Definisi Ekowisata}

Keberadaan alam yang masih asri dan potensi alam yang melimpah menjadikan tema ekowisata tepat diterapkan dalam perancangan ini

Prinsip dasar pengembangan ekowisata adalah (Mahdayani, 2009):

1. Pelestarian

Prinsip kelestarian pada ekowisata adalah kegiatan ekowisata yang dilakukan tidak menimbulkan kerusakan dan pencemaran lingkungan dan budaya setempat. Salah satu cara menerapkan prinsip ini adalah dengan cara menggunakan sumber daya lokal yang hemat energi dan dikelola oleh masyarakat sekitar. Tak hanya masyarakat, tapi wisatawan juga harus menghormati dan turut serta dalam pelestarian alam dan budaya pada daerah yang dikunjunginya (Mahdayani, 2009).

2. Pendidikan

Kegiatan pariwisata yang dilakukan sebaiknya memberikan unsur pendidikan. Ini bisa dilakukan dengan beberapa cara antara lain dengan memberikan informasi menarik seperti nama dan manfaat tumbuhan dan hewan yang ada di sekitar daerah wisata, atau kepercayaan dan adat istiadat masyarakat lokal (Mahdayani, 2009).

3. Pariwisata

Pariwisata adalah aktivitas yang mengandung unsur kesenangan dengan berbagai motivasi wisatawan untuk mengunjungi suatu lokasi. Ekowisata juga harus mengandung unsur ini. Oleh karena itu, produk dan, jasa pariwisata yang ada di daerah kita juga harus memberikan unsur kesenangan agar layak jual dan diterima oleh pasar (Mahdayani, 2009).

4. Ekonomi

Ekowisata juga membuka peluang ekonomi bagi masyarakat terlebih lagi apabila perjalanan wisata yang dilakukan menggunakan sumber daya lokal seperti transportasi, akomodasi dan jasa pemandu. Ekowisata yang dijalankan harus memberikan pendapatan dan keuntungan (profit) sehingga dapat terus berkelanjutan (Mahdayani, 2009).

5. Partisipasi masyarakat setempat

Partisipasi masyarakat akan timbul, ketika alam/budaya itu memberikan manfaat langsung/tidak langsung bagi masyarakat. Agar bisa memberikan manfaat maka alam/ budaya itu harus dikelola dan dijaga. Begitulah hubungan timbal balik antara atraksi wisata-pengelolaan manfaat yang diperoleh dari ekowisata dan partisipasi (Mahdayani, 2009).

\subsection{KAJIAN PERANCANGAN}

\section{a. Deskripsi Proyek}

Nama Proyek $\quad$ : Resort di Kabupaten Ciamis dengan Tema Ekowisata

Lokasi : Jalan Sukalena, Cijeunjing, Kabupaten Ciamis

Luas Lahan $\quad: 103.000 \mathrm{~m}^{2}$

Klasifikasi Bintang : Bintang satu

Jenis Proyek : Fiktif

\section{b. Tinjauan Lokasi}

Badan Perencanaan Pembangunan Daerah (BAPPEDA) Kabupaten Ciamis memiliki sepuluh prioritas rencana pembangunan setelah Pangandaran resmi berpisah dari Kabupaten Ciamis, salah satunya adalah pengembangan dalam sektor pariwisata (Edler, 1998). Menurut kepala BAPPEDA Kabupaten Ciamis, kunjungan wisatawan ke wilayah Kabupaten Ciamis menurun drastis karena memang pengaruh dari Pangandaran padahal, Kabupaten Ciamis ini memiliki banyak potensi pariwisata. 


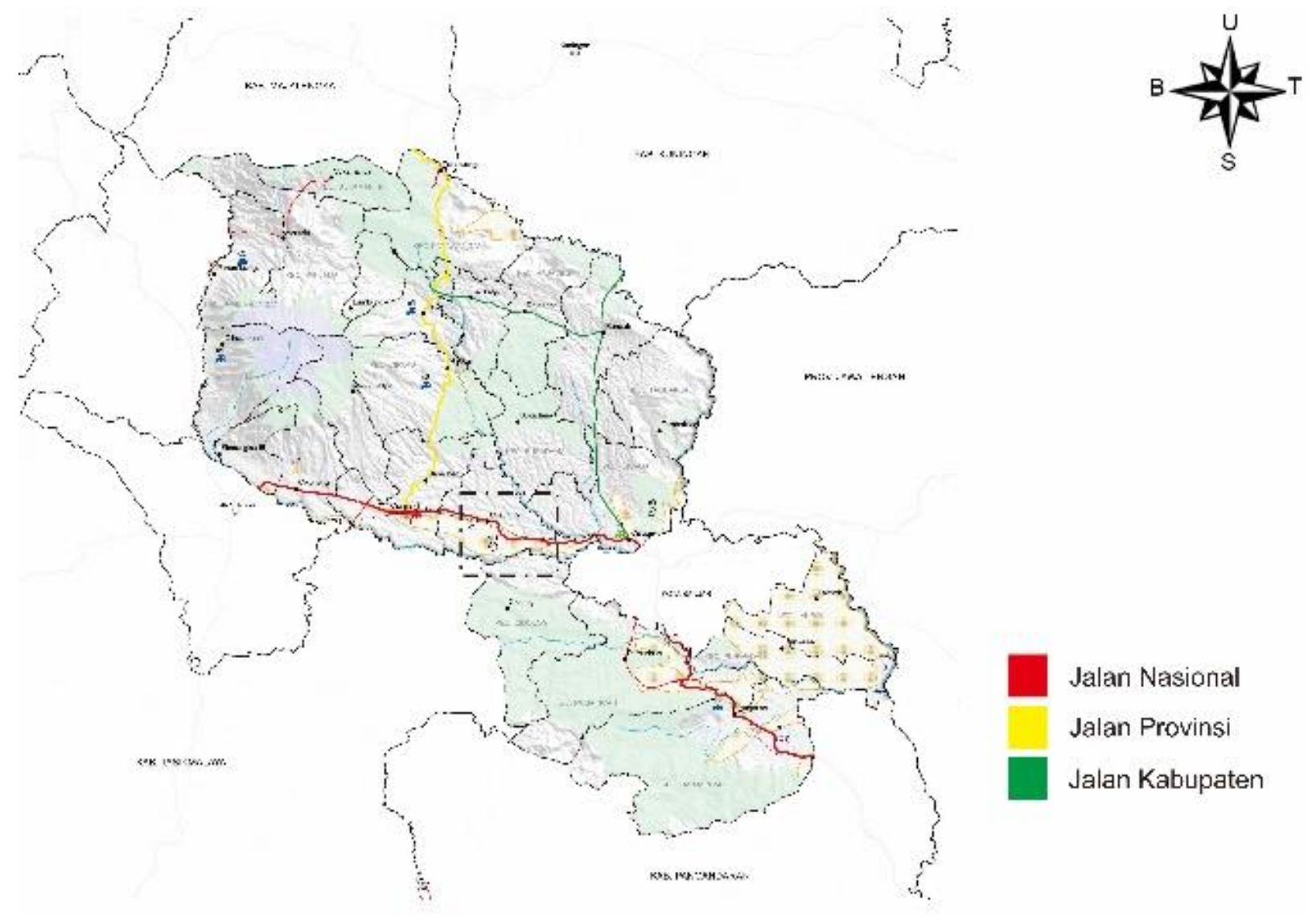

Gambar 3. 1 Lokasi Perancangan

Sumber: Analisis Penulis, 2018

\section{c. Lokasi Terpilih}

Kabupaten Ciamis terdiri dari 27 kecamatan.Menurut RTRW Kabupaten Ciamis Tahun 2011-2031, kecamatan Cijeugjing merupakan salah satu kecamatan yang diperuntukan sebagai kawasan pariwisata sudah terdapat objek wisata budaya yaitu Karangkamulyan dan Situs Gunung Susuru dan akan adanya pengembangan jaringan jalan arteri primer dan optimalisasi jaringan kereta api yang akan melewati kecamatan Cijeungjing mendukung Kecamatan Cijeungjing menjadi kawasan pariwisata. Lokasi perancangan berada tepat di Jalan Sukalena Kecamatan Cijeungjing Kabupaten Ciamis. 


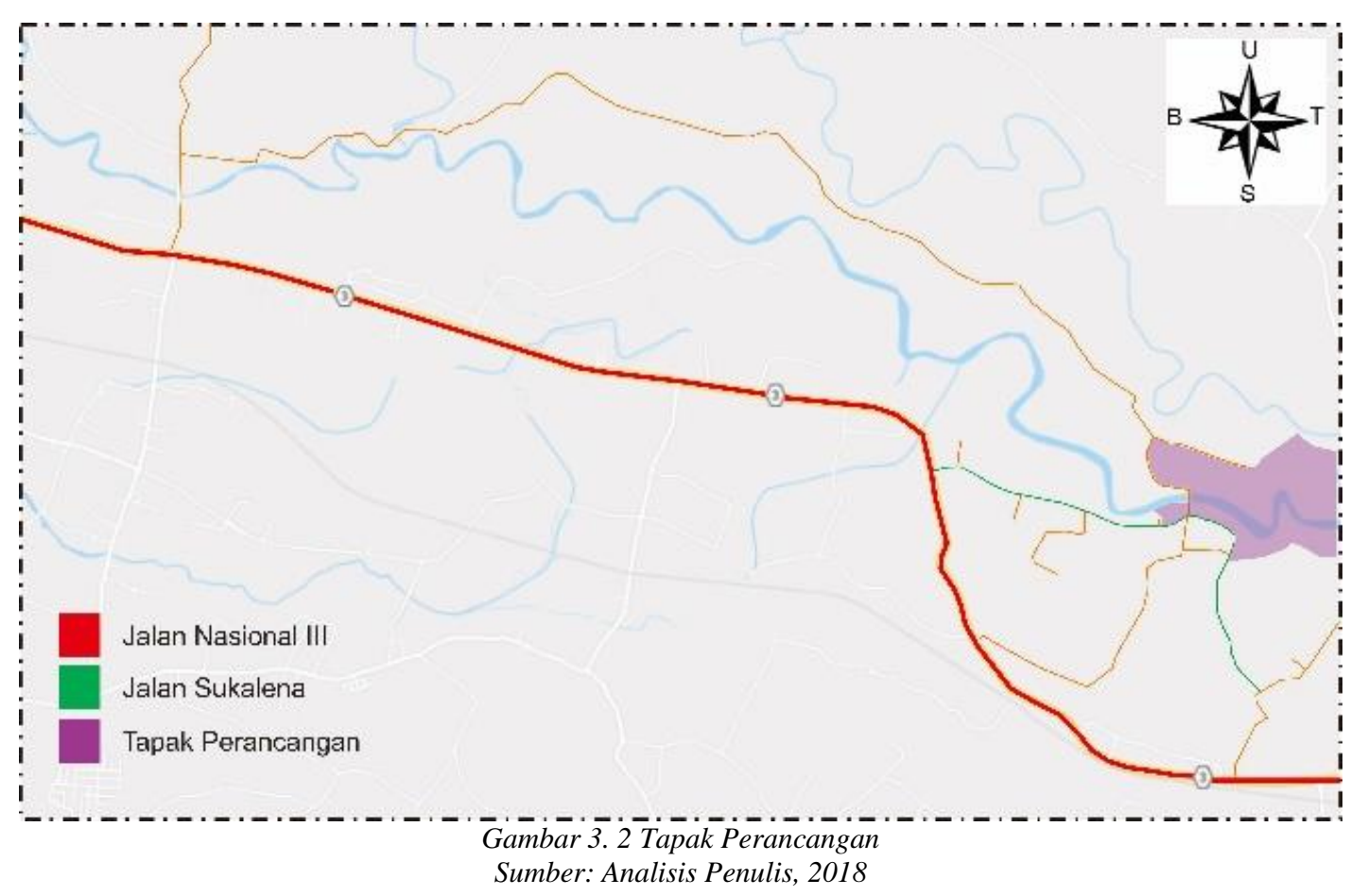

\subsection{KONSEP HASIL PERANCANGAN}

Hasil perancangan adalah hasil akhir dari rangkaian proses perancangan. Hasil perancangan tersebut di antaranya:

\section{a. Konsep Rancangan Tapak ( zoning makro )}

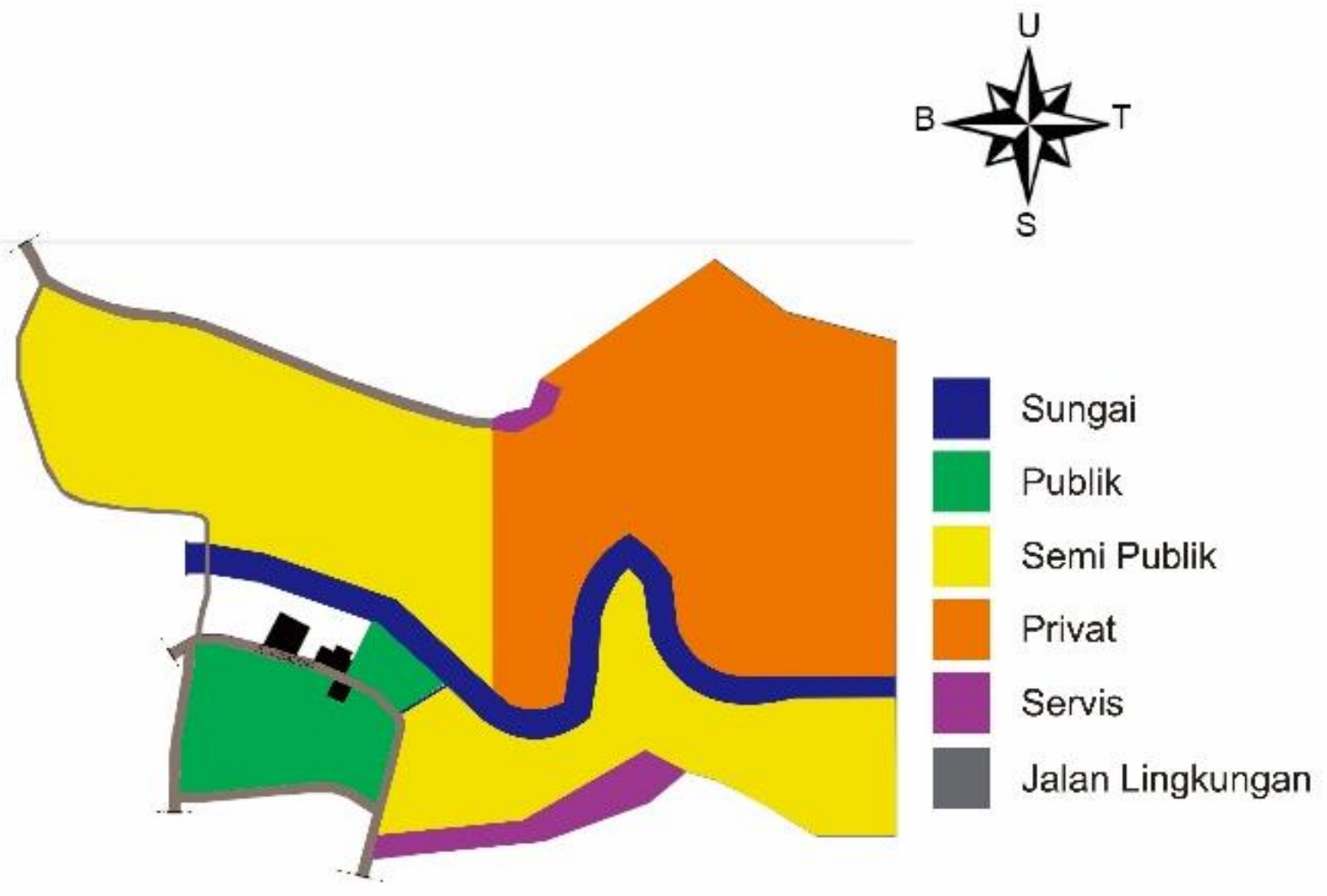

Gambar 3.3 Konsep Zonasi

Sumber: Analisis Penulis, 2018 
Kawasan resort dibagi menjadi zona publik, semi publik, privat, dan servis. Berikut penjelasan mengenai zona yang terdapat dalam kawasan resort:

- Publik

Zona publik merupakan area yang masih bisa di kunjungi oleh siapa pun seperti masyarakat atau pengunjung yang hanya ingin mengetahui informasi mengenai resort. Yang termasuk zona publik antara lain parkir, sungai, dan gedung penerimaan ( resepsionis).

- Semi Publik

Area ini merupakan area yang hanya bisa di akses oleh pengungjung resort dan pengunjung gedung pertemuan. Yang termasuk zona semi publik antara lain restoran, gedung pertemuan, area bertanam dan berkebun.

- Privat

Area ini merupakan area yang hanya bisa di akses oleh pengunjung resort yang menginap dan pengelola saja. Yang termasuk zona privat antara lain cottage, fasilitas olahraga seperti kolam renang, SPA, dan fitness.

- Area Servis

Area servis merupakan area pelayanan. Yang termasuk zona servis antara lain ruang genset, ruang pompa air bersih, loading dock, dan tempat penampungan sampah sementara.

Dari penjelasan di atas didapatkan rencana tapak sebagai berikut :

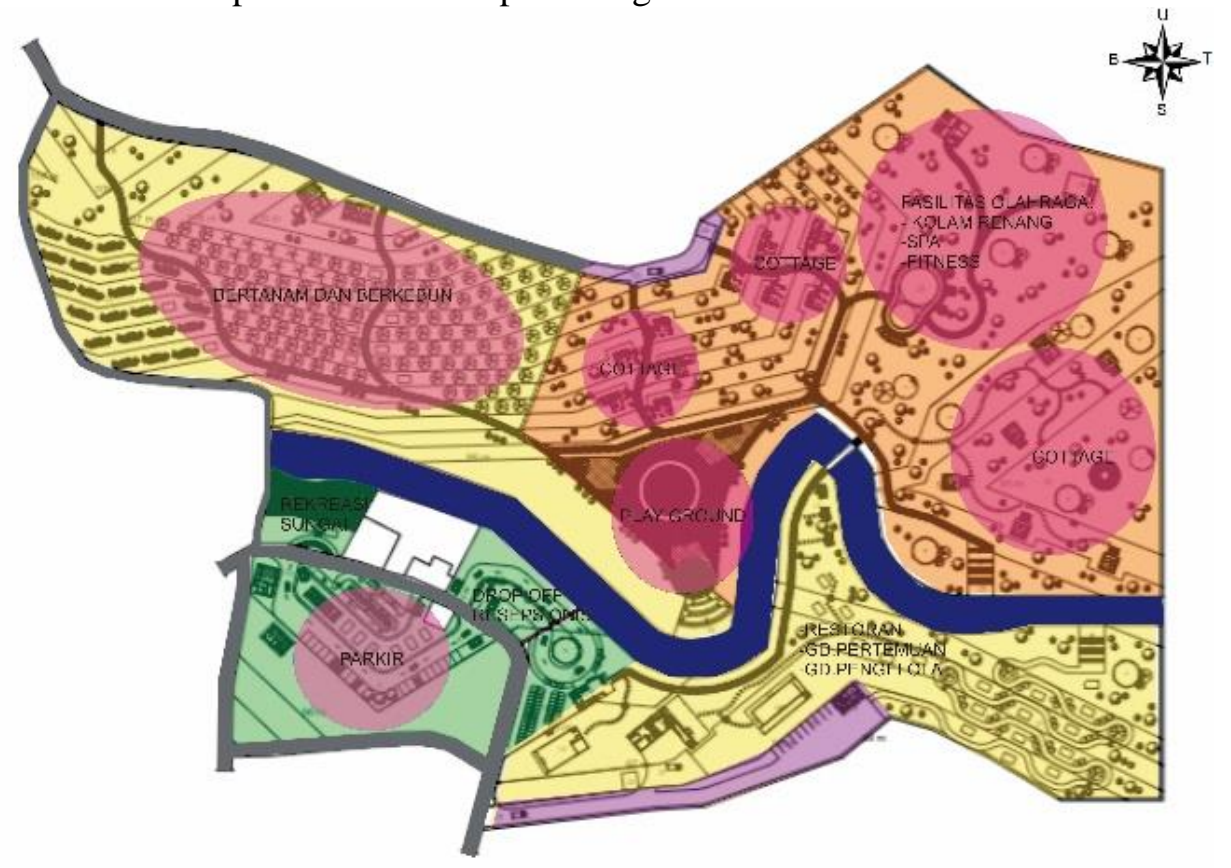

Gambar 3.4 Rencana Tapak

Sumber: Analisis Penulis, 2018

Pada area parkir terdapat toko souvenir, $\mathrm{km} / \mathrm{wc}$ umum, dan loket rekreasi sungai. Toko souvenir ini merupakan penerapan dari prinsip ekonomi dan partisipasi masyarakat. Toko souvenir memberikan ruang untuk masyarakat setempat agar dapat menjual sumber daya lokal yang nantinya hasil dari penjualan dapat membantu perekonomian masyarakat. Pemanfaatan sungai yang menjadi potensi alam di tapak perancangan menjadi rekreasi sungai berupa river tubing ( menyusuri sungai menggunakan ban) selain melestarikan juga memberikan ruang untuk masyarakat tempat sebagai tour guide dalam rekreasi sungai (Suhardiyanto. 2016). Area bertanam dan berkebun menjadi penerapan prinsip pendidikan dimana tamu akan belajar cara bertanam kacang tanah dan merasakan bekebun di kebun duku. 


\section{b. Sirkulasi dan Pencapaian}

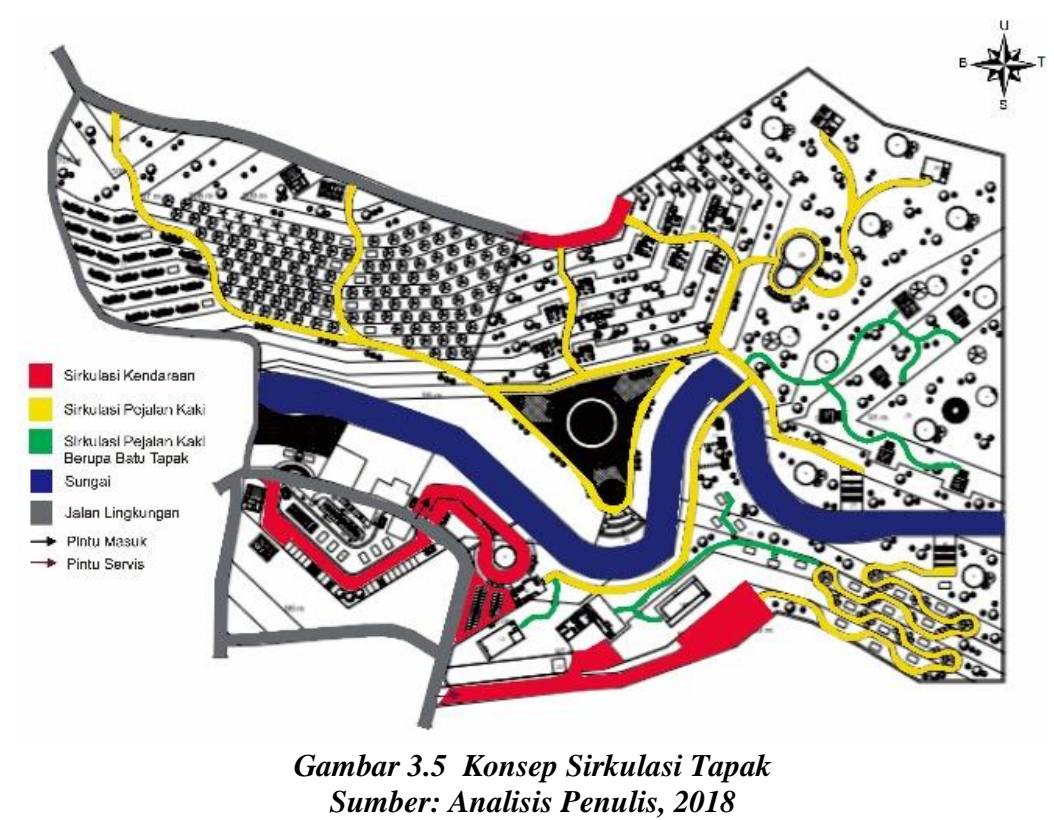

Pintu masuk utama berada di Jalan Sukalena ( tanda panah hitam). Pencapaian tamu resort menggunakan kendaraan hanya sampai drop off resepsionis, sedangkan pencapaian menuju penginapan dan fasilitas lainnya tamu hanya bisa berjalan kaki. Pencapaian menuju penginapan dan fasilitas lainnya dibuat hanya untuk pejalan kaki karena agar tamu yang datang dapat menikmati keindahan alam secara maksimal.Bentuk sirkulasi dalam tapak dibuat bergelombang dimana dalam logo Kabupaten Ciamis gelombang itu berarti sungai. Sesuai dengan sejarah, bahwa Kabupaten Ciamis merupakan pusat daerah kerajaan Galuh dimana Galuh itu berasal dari kata "sakaloh" yang berarti dari sungai asalnya. Bentuk sirkulasi yang dinamis juga ditujukan agar tamu yang datang ke resort dapat menikmati keindahan alam dan tidak merasakan bosan dan jauh saat berjalan di dalam kawasan resort.

Material yang digunakan pada sirkulasi kendaraan yaitu menggunakan paving block agar membedakan sirkulasi kendaraan di dalam kawasan dengan sirkulasi kendaraan di luar kawasan resort. Sedangkan material yang digunakan pada sirkulasi utama pejalan kaki yaitu menggunakan batu kali dan batu kali tapak pada sirkulasi pejalan kaki yang ingin menuju setiap bangunan.

\section{c. Konsep Bentuk Bangunan}

Bentuk massa bangunan akan dirancang mengikuti bentuk kontur tapak agar dapat memaksimalkan luas lahan dan menghindari adanya ruang mati. Bentuk dan orientasi bangunan yang mengikuti bentuk kontur tapak pun akan terlihat lebih alami. Berdasarkan RTRW Kabupaten Ciamis Tahun 2011-2031 disebutkan bahwa setiap bangunan hotel dan fasilitas penunjang pariwisata diharuskan menerapkan ciri khas arsitektur daerah setempat. Hal ini menjadikan konsep bentuk pada bangunan adalah kontekstual terhadap lingkungan tapak perancangan. 


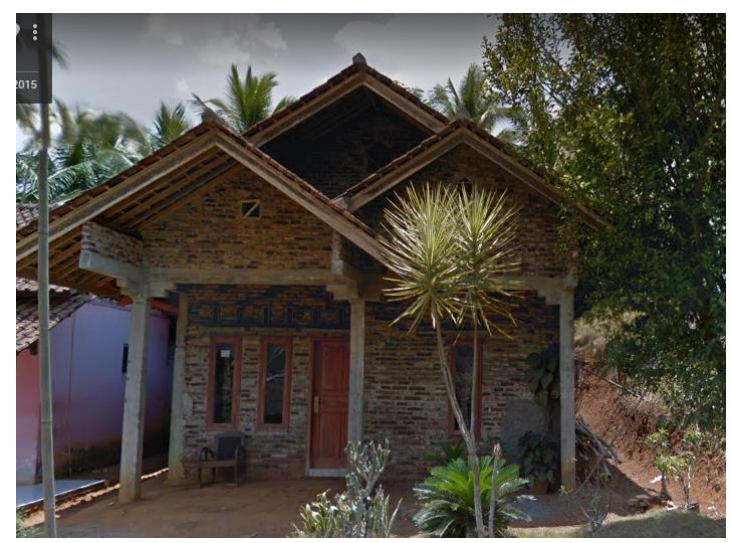

Gambar 3.6 Rumah Penduduk

Sumber : Google Images, 2018

Pada bangunan penginapan, bentuk bangunan menerapkan bentuk sederhana seperti bangunan rumah penduduk yang ada di lingkungan sekitar tapak. Penggunaan atap pelana yang mayoritas digunakan pada bangunan rumah penduduk dan penambahan atap di setiap fungsi ruang yang baru yang menjadi ciri khas akan diterapkan pada bangunan penginapan. Bangunan penginapan menerapkan dari bentuk bangunan rumah penduduk karena memiliki fungsi yang sama yaitu sebagai hunian dengan seperti itu, tamu akan merasa benar-benar sedang tinggal di daerah Ciamis. Dapat dilihat pada salah satu tipe cottage yaitu tipe suite. Tipe suite ini memiliki luas $154.21 \mathrm{~m} 2$. Terdiri dari ruang tidur, $\mathrm{km} / \mathrm{wc}$ dengan konsep semi outdoor, ruang keluarga, dan teras. Penggunaan atap yang berbeda pada fungsi ruang yang berbeda terlihat pada bentuk bangunan. Pada bagian ruang keluarga dan $\mathrm{km} / \mathrm{wc}$ menggunakan atap sorondoy yang melebar ke samping kanan dan kiri sedangkan pada fungsi ruang utama yaitu ruang tidur menggunakan atap pelana.
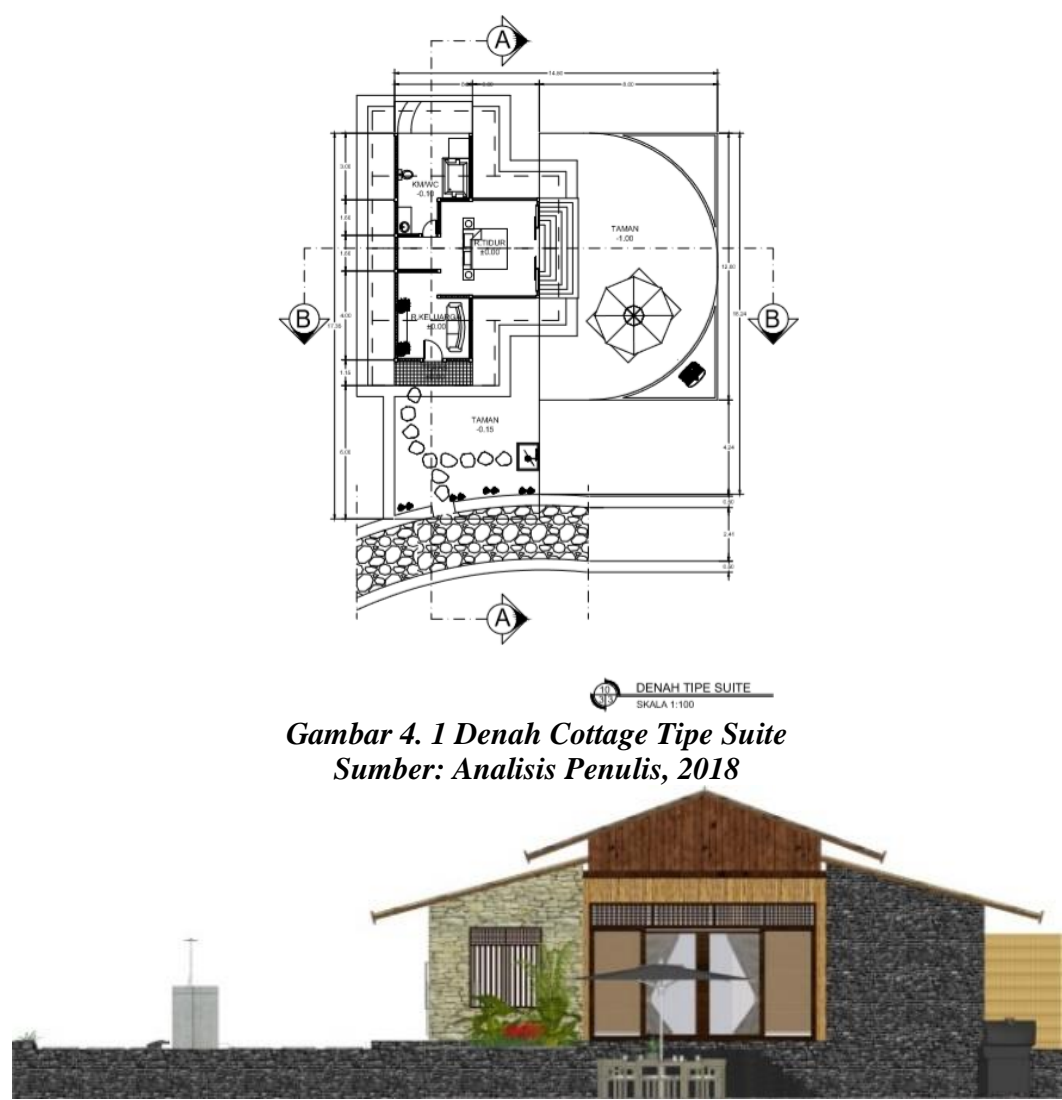

Gambar 3.7 Tampak Samping Kanan Tipe Suite

Sumber: Analisis Penulis, 2018

Bangunan penginapan dibagi menjadi tiga kawasan yaitu kawasan yang pemandangannya menghadap sungai (lingkaran ungu), kawasan yang pemandangannya menghadap ke kolam renang (lingkaran orannye), dan kawasan yang pemandangannya ke hutan (lingkaran cokelat). Setiap kawasan terdiri 
dari tiga tipe penginapan yaitu standar, deluxe, dan suite. Penempatan tipe bangunan penginapan dapat dilihat pada gambar diatas.

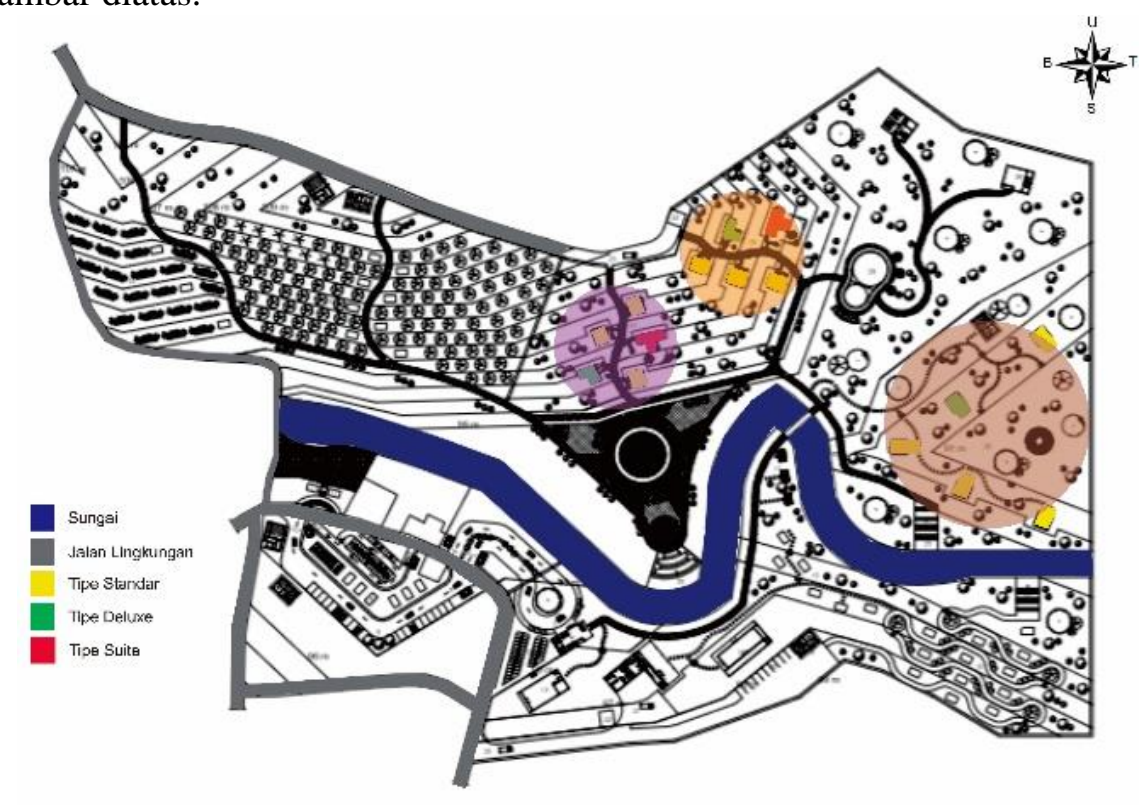

Gambar 3.8 Pemitakan Cottage

Sumber: Analisis Penulis, 2018

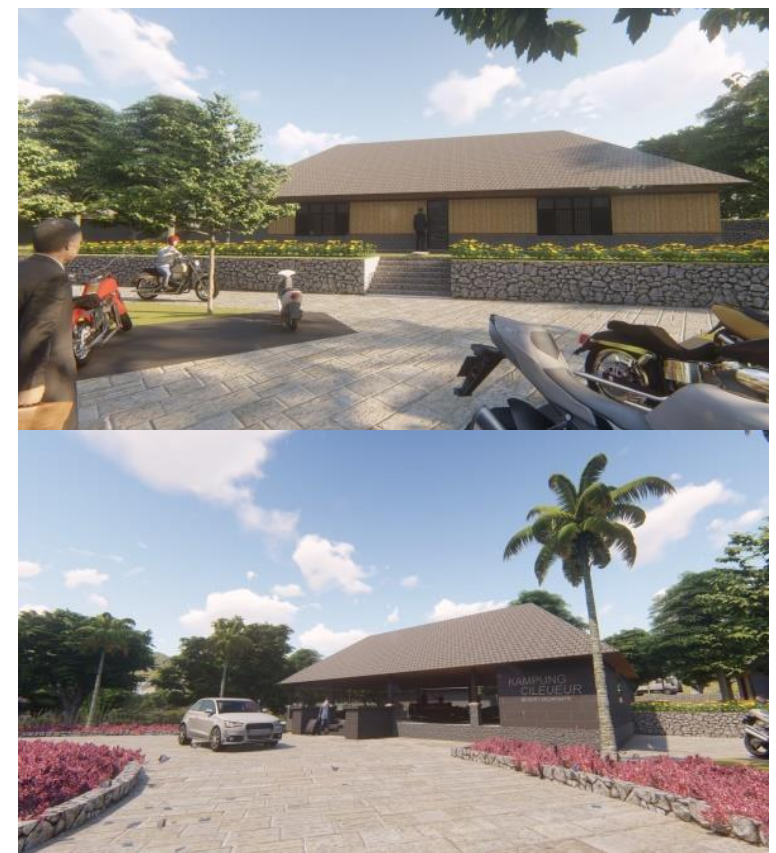

Gambar 3.9 Bangunan Penerima dan Pengelola Sumber: Dokumen Penulis, 2018

Untuk bangunan publik seperti bangunan penerima (resepsionis), gedung pertemuan, dan kantor pengelola menggunakan atap perisai. Atap perisai digunakan karena merupakan bentuk atap yang menjadi ciri khas Kabupaten Ciamis. Bentuk atap perisai digunakan di rumah adat Kampung Kuta dimana kita tahu Kampung Kuta masih ada sangkut paut dengan sejarah kerajaan Galuh dan digunakan pada bangunan pendopo Ciamis atau biasa disebut gedung negara yang di cap sebagai saksi bisu sejarah tatar Galuh. 


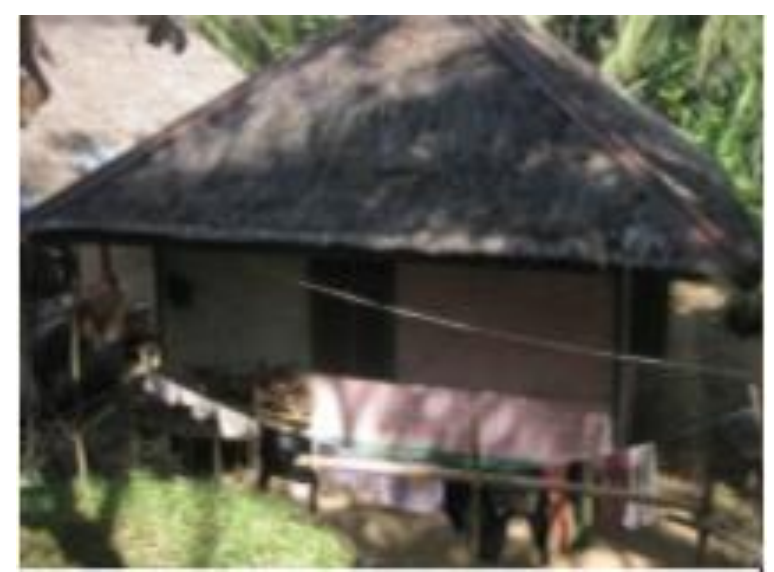

Gambar 3.10 Rumah Adat Kampung Kuta

Sumber: Analisis Penulis, 2018

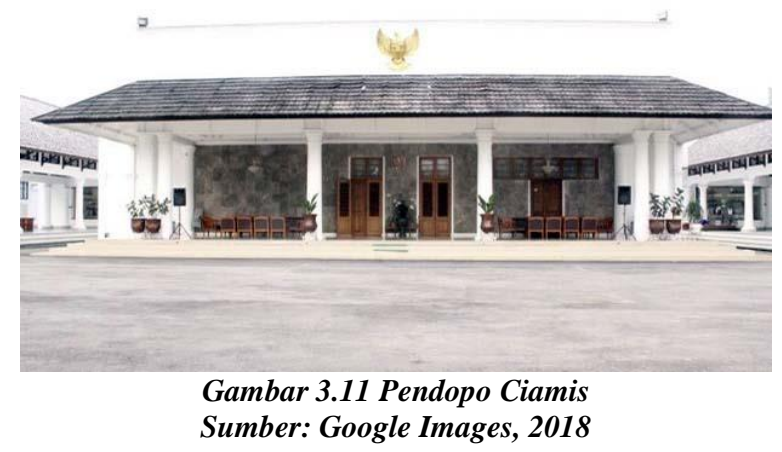

\section{KESIMPULAN}

Perancangan resort berlokasi di Kabupaten Ciamis tepatnya di Jalan Sukalena Kecamatan Cijeungjing. Tema Ekowisata diterapkan karena keberadaan alam yang masih asri dan potensi alam yang melimpah. Penerapan tema ekowisata diharapkan tidak menimbulkan kerusakan dan pencemaran lingkungan dan budaya setempat.

Resort ini dibagi menjadi 4 zonasi yaitu, publik diantaranya bangunan penerimaan (resepsionis), semi publik terdiri dari Gedung pertemuan, restoran, area bertanam dan berkebun, privat berupa bangunan penginapan (cottage) dan fasilitas olahraga, dan servis berupa ruang genset, ruang pompa air bersih, loading dock, dan tempat penampungan sampah sementara.

Konsep bentuk bangunan menerapkan ciri khas arsitektur daerah setempat yaitu kontekstual terhadap lingkungan tapak perancangan.Pada bangunan penginapan (cottage) menerapkan bentuk bangunan sederhana rumah penduduk yang ada di lingkungan sekitar tapak dengan menggunaan atap pelana dan penambahan atap di setiap fungsi ruang yang baru. Sedangkan untuk bangunan publik dan semi publik menggunakan atap perisai. Atap perisai digunakan karena merupakan bentuk atap yang menjadi ciri khas Kabupaten Ciamis yang digunakan di rumah adat Kampung Kuta dan bangunan pendopo Ciamis.

\section{Ucapan Terima kasih}

Penulis ucapkan terima kasih yang mendalam kepada seluruh dosen dan staf tenaga kependidikan Program Studi Arsitektur FTP UPI yang telah membantu dalam penyelesaian tugas akhir. Dan semua pihak yang tidak dapat Penulis disampaikan satu persatu.

\section{DAFTAR PUSTAKA}


[1] BAPPEDA Provinsi Jawa Barat. 2017. Ini Tiga Upaya Pemprov Jabar Dorong Industri Wisata. http://bappeda.jabarprov.go.id/ini-tiga-upaya-pemprov-jabar-dorong-industri-wisata/ (diakses pada 7 Agustus 2018).

[2] Dirjen Pariwisata. (1988). Pariwisata Tanah Air Indonesia.

[3] Edler D. 1998. Metric Handbook Planning and Design Data, Architectural Press, Oxford.

[4] Gee, Chuck Y. 1988. Resort Development and Management. New York: Waston-Guptil Publication.

[5] Gesivia H. 2015. Resor di Pulau Pahawang Lampung. Tugas Akhir . Diterbitkan . Sekolah Arsitektur, Perencanaan, dan Pengembangan Kebijakan Institut Teknologi Bandung : Bandung.

[6] Ischak, M., Setioko, B., \& Gandarum, D. N. (2018). Peran Place Identity Dalam Menciptakan Community Resiliance. Jurnal Arsitektur Zonasi, 1(2), 77-86. https://doi.org/http://10.17509/jaz.v1i2.12254

[7] L, Cindy, dkk, September 2017, “ Desitination Branding Kabupaten Ciamis Oleh Dinas Pariwisata dan Kebudayaan Provinsi Jawa Barat”. Komunikasi UNPAD. Volume XI, No. 02.

[8] Marlina E. 2008. Panduan Perancangan Bangunan Komersial,Penerbit ANDI Yogtakarta,Yogyakarta.

[9] Mahdayani, W. (2009). Panduan Dasar Pelaksanaan Ekowisata. Retrieved from http://library.binus.ac.id/eColls/eThesisdoc/Bab2DOC/2012-1-00126-MN Bab2001.doc.

[10] Plataran L' Harmonie. 2017-2018. Plataran Menjangan Resort \& SPA. https://www.plataran.com/hotels-resorts/plataran-menjangan (diakses pada 30 Juni 2018).

[11] Suhardiyanto. 2016, "Perancangan Sistem Plambing Instalasi Air Bersih Dan Air Buangan Pada Pembangunan Gedung Perkantoran Bertingkat Tujuh Lantai”. Jurnal Teknik Mesin (JTM). Volume 05, No.3. Oktober 2016. 